\title{
Familial expression of anti-Saccharomyces cerevisiae mannan antibodies in affected and unaffected relatives of patients with Crohn's disease
}

\author{
C L Sutton, H Yang, Z Li, J I Rotter, S R Targan, J Braun
}

Department of Pathology and Laboratory Medicine, UCLA School of Medicine, Los Angeles C L Sutton

J Braun

Division of Medical Genetics, Departments of Pediatrics and Medicine, Steven Spielberg Pediatric Research Center, Cedars-Sinai Medical Center

H Yang

$\mathrm{Z} \mathrm{Li}$

J I Rotter

IBD Research Center and Division of Gastroenterology, Cedars-Sinai Medical Center, Los Angeles, California, USA S R Targan

Correspondence to: Dr J Braun, Department of Pathology and Laboratory Medicine, CHS 13-222,

UCLA School of Medicine, Los Angeles, CA 90095-1732, USA

Accepted for publication 6 July 1999

\begin{abstract}
Background-Crohn's disease is a familial disorder, and antiglycan antibodies to the cell wall mannan of Saccharomyces cerevisiae (ASCA) are highly correlated with Crohn's disease.

Aims-To determine whether there is a familial pattern for expression of serum levels of anti-mannan Ig, and whether this trait is expressed in clinically unaffected Crohn's disease family members.

Methods-349 patients with Crohn's disease, 87 Crohn's disease affected relatives, 333 inflammatory bowel disease (IBD) free relatives, 58 spouses, and 190 healthy control patients were studied. Serum IgG and $\operatorname{IgA}$ binding activity to $S$ cerevisiae cell wall mannan was quantitated by ELISA.

Results-A high percentage of patients with Crohn's disease $(51.9 \%)$ and affected family members $(56.3 \%)$ were seropositive for anti-mannan Ig, compared with the normal control population $(3.7 \%)$. Seropositive and seronegative phenotypes of Crohn's disease probands were correlated among all affected relatives, and this association was stronger in affected first degree relatives. Statistical intraclass correlations of quantitative anti-mannan Ig levels revealed significantly less variation within, rather than between families. A significant familial aggregation was observed for affected relatives; this was even stronger for unaffected relatives. While a significant familial aggregation was observed among unaffected siblings pairs, there was no significant correlation among marital pairs.

Conclusion-Results show that antimannan Ig in family members affected and unaffected with Crohn's disease is a familial trait for both affected and unaffected relatives. The lack of concordance in marital pairs indicates that familiality is due in part to a genetic factor or childhood environmental exposure.

(Gut 2000;46:58-63)
\end{abstract}

Keywords: Crohn's disease; inflammatory bowel disease; ulcerative colitis; anti-mannan antibodies; intraclass correlation; statistical genetics

There is a recent resurgence of interest in the interplay between environmental and genetic factors in the pathogenesis of Crohn's disease. Environmentally, Crohn's disease has been directly and indirectly associated with various enteric microorganisms. Intestinal inflammation in Crohn's disease is notable for its frequent responsiveness to antibiotics and susceptibility to bacterial faecal flow. ${ }^{1-5}$ Common intestinal colonists and novel pathogens have been implicated in Crohn's disease by direct detection or by disease associated antimicrobial immune responses. ${ }^{4-12}$ In most animal models of chronic colitis, luminal microorganisms are a necessary cofactor for disease. ${ }^{13-16}$ Several dietary antigens have also been implicated in the pathogenesis of inflammatory bowel disease (IBD). ${ }^{17-20}$

Differential host susceptibility to Crohn's disease has been documented by ethnic predisposition, and familial and twin aggregation. ${ }^{21-26}$ Crohn's disease is an oligogenic/polygenic disorder, and a variety of human genes and loci have been implicated in disease susceptibility. $^{27-36}$

Immune responses are an important nexus of environmental factors and host genetics, and disease specific marker antibodies in IBD have gained attention as possible manifestations of the disease related immune response. In ulcerative colitis, high serum levels of antineutrophil cytoplasmic antibodies (pANCA) are strongly correlated with disease, and several studies have observed elevated frequency of pANCA seropositivity in unaffected relatives of patients with ulcerative colitis. These findings are interpreted as evidence that pANCA expression is an immunological trait related to disease susceptibility. ${ }^{37-40}$ In Crohn's disease, serum reactivity to the cell wall mannan polysaccharide of Saccharomyces cerevisiae (ASCA) is a serological marker for a majority of individuals with Crohn's disease. ${ }^{41-45}$ The specificity of the anti-mannan marker antibody for Crohn's disease (versus ulcerative colitis and other colitides) indicates that its expression is not a simple epiphenomenon of intestinal insult. The question addressed by the present study is whether levels of anti-mannan antibodies are not only disease associated, but also represent a familial immunological trait expressed in unaffected family members. Using quantitative marker antibody determination and intraclass correlation analysis, this study reveals that anti-mannan levels are a familial trait, with a possible genetic component to their pattern of expression.

Abbreviations used in this paper: ASCA, anti-Saccharomyces cerevisiae mannan antibodies; IBD, inflammatory bowel disease; pANCA, perinuclear antineutrophil cytoplasmic antibodies. 
Table 1 Distribution of family size in the study population

\begin{tabular}{|c|c|c|c|c|c|}
\hline \multicolumn{3}{|c|}{ Proband + first degree only } & \multicolumn{3}{|c|}{ Proband + all relatives } \\
\hline Size & Frequency & Percentage & Size & Frequency & Percentage \\
\hline 2 & 23 & 18 & 2 & 22 & 17 \\
\hline 3 & 31 & 25 & 3 & 29 & 23 \\
\hline 4 & 30 & 24 & 4 & 26 & 21 \\
\hline 5 & 18 & 14 & 5 & 20 & 16 \\
\hline 6 & 16 & 13 & 6 & 14 & 11 \\
\hline 7 & 4 & 3 & 7 & 7 & 6 \\
\hline \multirow[t]{3}{*}{8} & 3 & 2 & 8 & 6 & 5 \\
\hline & & & 9 & 1 & 1 \\
\hline & & & 11 & 1 & 1 \\
\hline Total & 125 & 100 & Total & 126 & 100 \\
\hline
\end{tabular}

Table 2 Frequency of individuals positive for anti-mannan Ig

\begin{tabular}{lrllll}
\hline & $n$ & IgA (\%) & IgG (\%) & Both (\%) & Either (\%) \\
\hline Patients with CD & 349 & 44.4 & 41.8 & 34.4 & 51.9 \\
Affected relatives & 87 & 46.0 & 48.3 & 37.9 & 56.3 \\
Unaffected relatives & 333 & 4.5 & 6.6 & 1.8 & 9.3 \\
Unaffected spouses & 58 & 5.2 & 5.2 & 1.7 & 8.6 \\
Patients with UC & 249 & 7.6 & 4.0 & 2.4 & 9.2 \\
Healthy controls & 132 & 1.5 & 2.3 & 0 & 3.8 \\
\hline
\end{tabular}

Serum antimannan Ig levels were quantitated, and positive values were tabulated as greater than $40 \mathrm{EU} / \mathrm{ml}$ and $20 \mathrm{EU} / \mathrm{ml}$ for IgG and IgA respectively.

$\mathrm{CD}$, Crohn's disease; UC, ulcerative colitis.

\section{Materials and methods}

POPULATION

Serum aliquots were obtained from the IBD serum research archive at Cedars-Sinai Medical Center; the patient demography of this archive and method of selecting probands and relatives from the archive has been reported previously. ${ }^{27} 3839$ Subjects included 349 patients with Crohn's disease, 98 Crohn's disease affected relatives, and 333 IBD free relatives. Relatives included first degree relatives (parents, siblings, and children), and other more distant relatives (uncles, nieces, grandparents, etc). There was a total of 420 relatives from 126 Crohn's disease only families. Within these relatives, only 38 were "other distant relatives". Among 382 first degree relatives, 188 were parents, 54 were children, and 140 were siblings of Crohn's disease probands. The family size of first degree relatives ranged from two to eight; the size was three or four in about $50 \%$ of families. There was minimal difference in the family size distribution between the first degree relatives only group and the all relatives group (table 1).

A concurrent set of control subjects was also studied from this archive, including 249 patients with ulcerative colitis, and 190 healthy subjects who had no family history of ulcerative colitis or Crohn's disease. Of these 190 healthy controls, 58 were spouses of Crohn's disease probands. For this study, samples were obtained from Crohn's disease only familiesthat is, those lacking any family history of ulcerative colitis. The relative rarity of some of these samples necessitated the use of serum

Table 3 Family aggregation of anti-mannan levels

\begin{tabular}{llllll}
\hline & \multicolumn{2}{l}{ Affected siblings } & & \multicolumn{2}{c}{ Unaffected siblings } \\
\cline { 2 - 3 } Phenotype & $t^{\star}$ & p value & & $t^{\star}$ & p value \\
\hline IgA & 0.29 & 0.02 & & 0.30 & 0.006 \\
IgG & 0.27 & 0.03 & & 0.35 & 0.002 \\
\hline $\mathrm{t}^{\star}=$ & intraclass correlation coefficient. & &
\end{tabular}

that had been stored for between one month and 11 years at $-80^{\circ} \mathrm{C}$. All subject recruitment and experimental studies were performed under protocols approved by the Cedars-Sinai Medical Center and UCLA Institutional Review Boards.

ANTI-MANNAN ANTIBODY (ASCA) DETERMINATION

Serum anti-mannan Ig levels were quantitated using a standard calibrated enzyme linked immunosorbent assay (ELISA) system (Prometheus, San Diego, California, USA). Antimannan Ig cut off values defining seropositivity in this assay (40 EU/ml IgG anti-mannan, and $20 \mathrm{EU} / \mathrm{ml}$ IgA anti-mannan) have been previously optimised for Crohn's disease diagnostic accuracy. Both quantitative (Ig level) and qualitative (seropositivity) data were analysed to evaluate the distribution of this antibody.

\section{ANALYSIS OF GROUP AGGREGATION}

The comparisons of seropositivity prevalence in different groups were conducted by $\chi^{2}$ test. The Ig levels were transformed by logarithm before any statistical test.

ANALYSIS OF FAMILIAL AGGREGATION

Anti-mannan antibody is significantly associated with Crohn's disease. To reduce the confounding effect of the presence of the disease, familial aggregation was evaluated in two separate groups: those family members affected with Crohn's disease, and those who were not affected with Crohn's disease. The association of proband seropositivity with affected relative seropositivity was evaluated by $\chi^{2}$ test. In addition, the significance of the family effect was determined via the $F$ statistic. This compares variability among families with within family variability, and was separately determined for affected and unaffected siblings.

INTRACLASS CORRELATION ANALYSIS

An intraclass correlation coefficient $\left(t^{\star}\right)$ is defined as $t^{\star}=\sigma_{B}^{2} /\left(\sigma_{B}^{2}+\sigma^{2}{ }_{w}\right){ }^{46}$ The proportion of the total variance of an observation that occurs among groups in this study was represented by different families. When $t^{\star}$ is high, most of the variation is among families, and there is little variation within families. Therefore, a large $t^{\star}$ implies that siblings are more similar to one another than to randomly selected individuals. $t^{\star}$ is calculated by $\left(\mathrm{MSE}_{\mathrm{B}}\right.$ $\left.-\mathrm{MSE}_{\mathrm{w}}\right) /\left[\mathrm{MSE}_{\mathrm{B}}+(\mathrm{n}-1) \mathrm{MSE}_{\mathrm{w}}\right]$, where MSE is the mean square error, $\mathrm{B}$ is that among families, $\mathrm{W}$ is that within families, and $\mathrm{n}$ is average sibship size. The average sibship size is calculated as $\mathrm{n}=[1 /(\mathrm{k}-1)]^{\star}\left[\mathrm{N}-\left(\Sigma \mathrm{n}_{\mathrm{i}}{ }^{2} / \mathrm{N}\right)\right]$, where $\mathrm{k}$ is the number of families, $\mathrm{N}$ is the total number of subjects, and $n_{i}$ is the number of siblings in each family. ${ }^{47}$ The error terms for among and within families were derived from the general linear model. All statistical analyses were performed with programs of the SAS Institute, v.6.12 (Statistical Analysis System, Cary, North Carolina, USA).

Correlations among each type of relationship in a family were calculated by the FCOR program in the Statistical Analysis for Genetic 


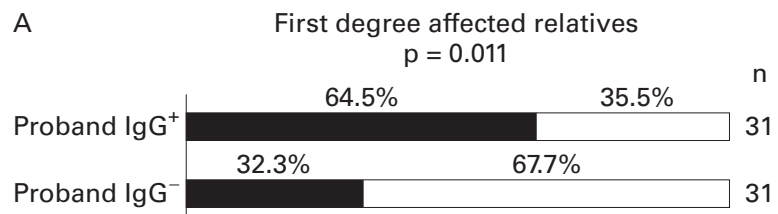

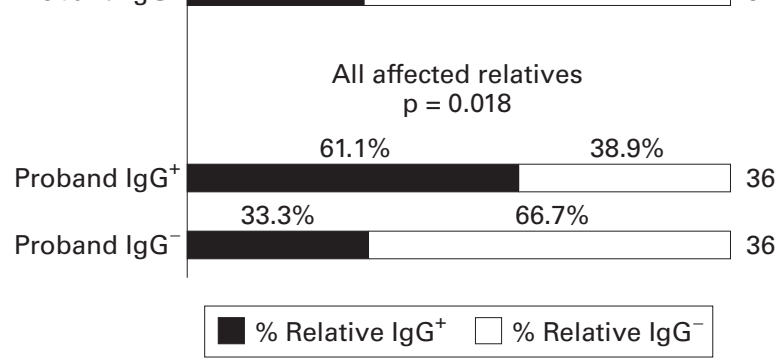

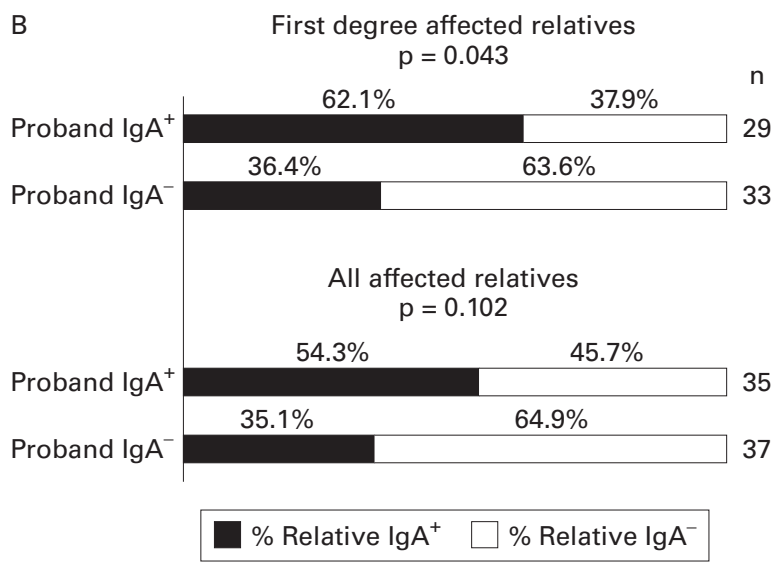

Figure 1 Concordance of IgG and IgA anti-mannan seropositivity in probands and affected relatives: (A) anti-mannan IgG; (B) anti-mannan IgA.
Epidemiology (SAGE) package (Rammelkamp Center for Education and Research, Case Western Reserve University, Cleveland, Ohio, USA) ${ }^{48}$ The calculated correlation coefficient in each group was tested for its statistical significance under the null hypothesis of no correlation.

\section{Results}

ANTI-MANNAN Ig SEROPOSITIVITY RATES

The levels of anti-mannan IgG and IgA activity were determined for a large sample set of Crohn's disease probands, relatives, spouses, and ulcerative colitis and healthy non-IBD controls. Table 2 shows the seropositive frequencies for all populations of the current study. The frequency of patients with Crohn's disease seropositive for $\operatorname{IgG}$ or $\mathrm{IgA}$ antimannan antibodies was $53 \%$ of 436 total patients with Crohn's disease (Crohn's disease index patients + unaffected relatives). This frequency was similar to previously reported patient groups. ${ }^{42445}$

Seropositivity rates were much lower in healthy non-IBD controls $(3.8 \%)$ and patients with ulcerative colitis $(9.2 \%) \quad(p<0.0001$ for each group compared with patients with Crohn's disease). The low rates in these populations agree with previous studies. ${ }^{42}$ In addition, the frequency of anti-mannan Ig positive subjects was slightly elevated in unaffected relatives $(9.3 \%)$ and spouses $(8.6 \%)$ when compared with healthy controls $(4.0 \%)$. However, these differences were not statistically significant at this sample size.

\section{CONCORDANCE OF SEROPOSITIVITY RATES IN} FAMILIES

Our first test of familiality was based on the hypothesis that anti-mannan seropositivity and seronegativity define distinct biological subsets of Crohn's disease. Accordingly, seropositive and seronegative Crohn's disease probands were identified, and the frequency of IgG and IgA seropositivity was calculated for their affected relatives. For both seropositive and seronegative Crohn's disease probands, the frequency of concordant affected relatives was about twice that of non-concordant relatives. These concordances were significant for both IgG and IgA, and were higher among first degree relatives (parents, children, or siblings; fig 1). The concordance was observed for both first degree and more distant relatives, and quantitatively ( $9 \%$ and $12 \%$, respectively) was not statistically different. However, it should be noted that the number of distant relatives was small (13 affected and 25 unaffected).

INTRAFAMILY CORRELATION OF QUANTITATIVE ANTI-MANNAN Ig LEVELS

Our second test of familiality evaluated the prediction that quantitative anti-mannan Ig levels aggregate within families. This evaluation differed from the seropositive concordance test, because it allowed us to analyse the large group of unaffected family members whose anti-mannan Ig levels were measurable but below the cut off for seropositivity.

Table 3 and fig 2 show the results of this analysis. Anti-mannan levels were plotted for each subject, and grouped vertically by family. Families were ranked by the family mean antimannan Ig. Family means ranged five- and twofold in unaffected family members (IgG and IgA, respectively), and 16-fold in affected family members (both IgG and IgA). Using the intraclass correlation method, high correlation coefficients ( $t^{\star}$ values) were calculated for all four groups. These values were significant in the affected groups $(p=0.03$ and $p=0.02$ for IgG and IgA), and were even more significant in the unaffected groups $(p=0.002$ and $\mathrm{p}=0.006$ ). These findings indicated that antimannan Ig levels varied less within families than between families, and hence displayed familial aggregation.

COMPARISON OF SIBLING AND MARITAL PAIRS

To assess the contribution of genetics independent of environment, correlations ( $t^{\star}$ values) were calculated for anti-mannan Ig in clinical unaffected marital pairs (representing purely environmental contribution) and sibling pairs (representing environmental as well as genetic contribution). As fig 3 shows, antimannan Ig were highly correlated within the sibling pairs, but a significant correlation was not observed for marital pairs. These findings indicated that the familiality of anti-mannan Ig levels reflected a factor distinct from the family residential environment. 

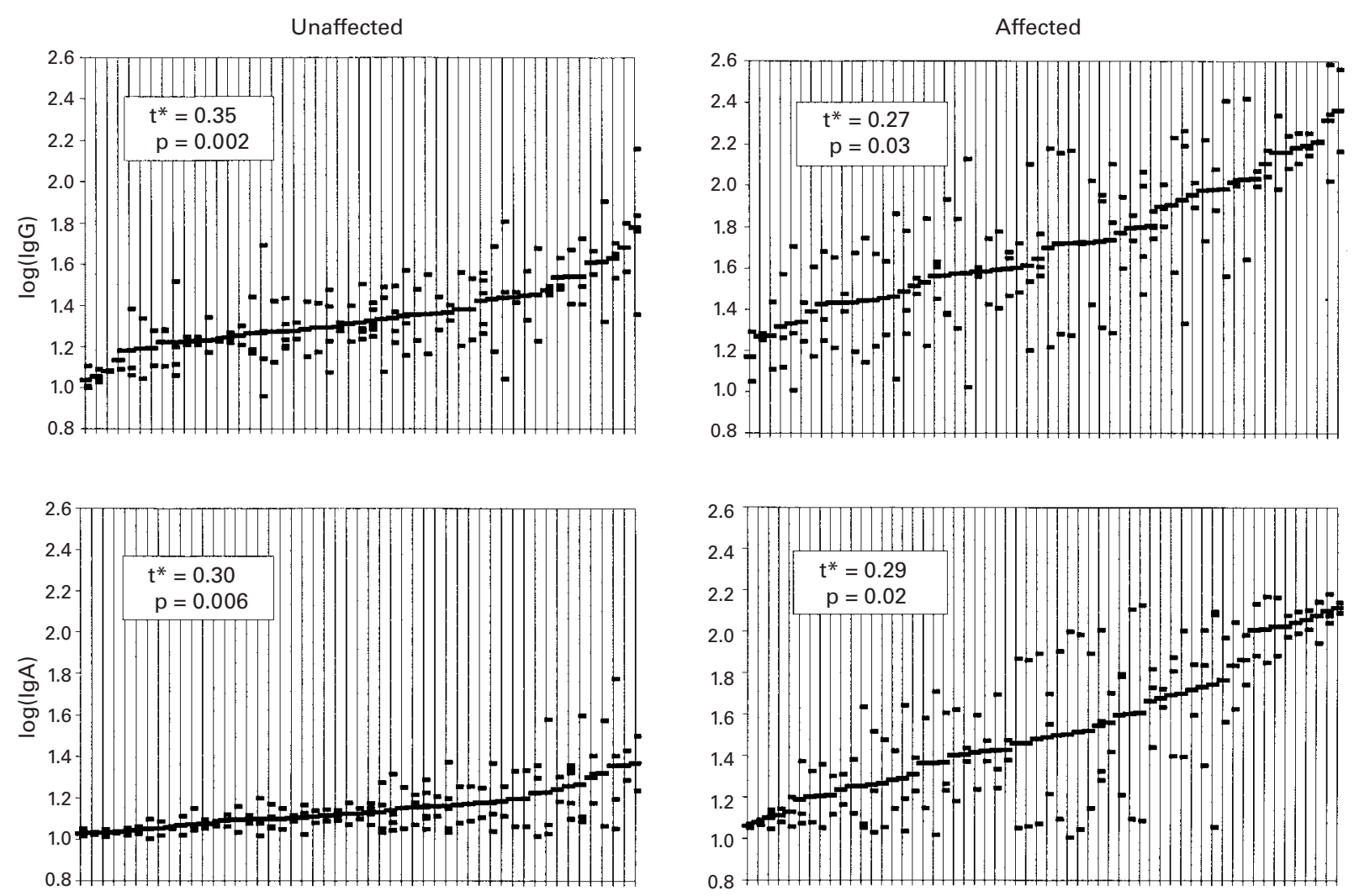

Families ranked by family mean anti-mannan Ig

Figure 2 Anti-mannan Ig levels in families. Anti-mannan Ig values are shown for each subject, grouped vertically by family. Families are ranked by family mean anti-mannan Ig (solid line).

\section{Discussion}

The present study shows that expression of the anti-mannan marker antibody (ASCA) is a familial trait in families of patients with Crohn's disease. This conclusion is based on two types of phenotypic analysis: concordance of seropositivity rates in affected family members with seropositive and seronegative Crohn's disease probands; and intraclass correlation of anti-mannan Ig levels in both affected and unaffected family members. It also presents two lines of evidence supporting a genetic component for familial marker antibody expression: seropositivity rates were more concordant in first degree versus all relatives;

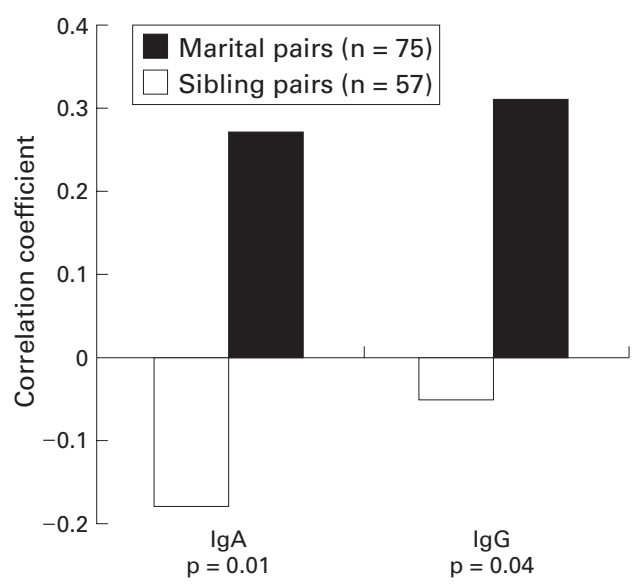

Figure 3 Correlations of anti-mannan Ig levels in marital pairs and sibling pairs. and quantitative anti-mannan levels were significantly correlated in sibling but not marital pairs.

This study was based on quantitation of anti-mannan Ig levels in a large patient serum archive of affected and unaffected family members (1017 subjects). Mean anti-mannan Ig levels and rates of seropositivity for Crohn's disease probands and their affected relatives were significantly higher than in Crohn's disease free and clinically normal populations. This confirmed the fundamental association between this marker antibody and the presence of Crohn's disease.

If anti-mannan activity were familial, then the antibody status of the affected relative should correlate with the status of the Crohn's disease proband. Among all relatives, this categorical correlation was significant for IgG (correlation table analysis of $\mathrm{p}=0.018$ and $\mathrm{p}=0.102$ for $\operatorname{IgG}$ and $\operatorname{IgA}$, respectively). Among affected first degree relatives, a strong correlation was observed for both IgG and IgA $(p=0.01$ and $p=0.04)$. The low frequency of seropositivity among unaffected relatives ( $4.5 \%$ for $\operatorname{IgA}, 6.6 \%$ for $\operatorname{IgG}$ ) prevented us from using this analytical method for that subgroup. We note that in other recent studies, the elevation of seropositivity in unaffected relatives reached statistical significance. ${ }^{42} 4445$

In order to evaluate quantitatively whether anti-mannan levels are familially associated distinct from disease, we determined the intraclass correlation coefficients for both affected and unaffected individuals. This comparison 
method utilises quantitative rather than categorical (positive-negative) traits. For this reason, it is better for assessing groups with low rates of the phenotype in question (in this case, marker antibody levels in unaffected family members). The intraclass correlation coefficient compared the variation in anti-mannan levels between and within groups. The correlation coefficient $\left(t^{\star}\right)$ for this comparison will range from 0 to 1 ; the low value reflects a trait without intragroup specificity, and the latter represents a trait entirely segregated within a group. Among affected family members, anti-mannan levels were correlated more within families than between families $\left(t^{\star}=0.27\right.$ and $t^{\star}=0.29, p=0.03$ and $\mathrm{p}=0.02$, for $\operatorname{IgG}$ and $\operatorname{Ig} \mathrm{A}$, respectively). Notably, this correlation was even stronger among unaffected family members $\left(t^{\star}=0.35\right.$ and $t^{\star}=0.30, p=0.002$ and $\left.p=0.006\right)$.

These findings are impressive when compared with a classic study utilising intraclass correlation of in vivo insulin action as a marker for genetic susceptibility to type II diabetes. In that study of the Pima Indian population, intraclass correlation also revealed an increased concordance of fasting insulin and insulin action (glucose uptake on insulin infusion) within families rather than between families $\left(t^{\star}=0.35\right.$ and $t^{\star}=0.42, \quad p<0.001$ and $p<0.0001$, respectively). ${ }^{49}$ These parameters of insulin sensitivity are considered major intermediate phenotypes in type II diabetes genetic susceptibility, and familiality contributes $12 \%$ and $34 \%$ (fasting insulin and insulin action) of the total variance in these phenotypes. In the present study, similar rates of intraclass correlation were observed for anti-mannan levels in families of Crohn's disease probands. Accordingly, this analysis validates anti-mannan Ig levels as a familial trait in Crohn's disease families independent of clinical disease.

Two lines of evidence suggest a genetic contribution to the familial pattern of anti-mannan expression. Firstly, anti-mannan Ig seropositivity was more strongly correlated in first degree versus all relatives. Secondly, anti-mannan Ig levels were significantly correlated in genetically similar (siblings) but not genetically dissimilar (marital) pairs. However, environmental factors may also contribute to these correlations. For example, probands and their first degree relatives share a distinct childhood residential exposure and a long subsequent surveillance period.

Some studies have proposed that the association of Crohn's disease and anti-mannan Ig is due to antigenic challenge secondary to increased inflammation related epithelial permeability. ${ }^{250}$ ASCA levels may decrease after surgical resection of involved intestinal segments, presumably by reduction of microbial challenge from these sites. ${ }^{51}$ In contrast, a substantial fraction of patients with Crohn's disease are seronegative, and the present study shows that the seronegative phenotype in patients with Crohn's disease is a familial trait. In addition, this study reveals a strong intraclass correlation of marker antibody expression among unaffected family members. These observations suggest that anti-mannan
Ig expression is a familial immunological trait which can be independent of disease associated antigenic exposure. The relative impact of antigenic challenge and familial susceptibility could be further assessed by a longitudinal study of ASCA level stability in individuals from affected and unaffected families.

The familial pattern of anti-mannan antibodies in Crohn's disease has been reported recently by Sendid et $a .^{45}$ That study also observed that elevated anti-mannan seropositivity levels are a familial trait in Crohn's disease, based on a French study population. The present study reflected the same conclusion using a very large population of family members and appropriate controls (1017 individuals). This study also addressed two additional issues. Firstly, it introduced a second analytical method (intraclass correlation of anti-mannan Ig levels) which revealed that marker antibody expression was a trait of family members clinically unaffected by Crohn's disease. Secondly, it introduced evidence suggesting a genetic component to this trait.

There are two general implications of these findings. Firstly, as increased disease susceptibility is observed in relatives of patients with Crohn's disease, anti-mannan levels may be valuable as a preclinical marker for Crohn's disease. The feasibility of this strategy will depend on developing and validating cut off values with clinical useful predictive values. Secondly, the concordance of seropositivity (or seronegativity) among Crohn's disease probands and affected relatives suggests that these represent two immunological disease subsets. The concept of biologically distinct IBD subsets is supported by genetic, clinical, and therapeutic evidence. It will be important to determine whether these anti-mannan seropositive and seronegative subsets differ in prognosis, response to therapy, and established genetic markers in this disease. Such factors are also potentially confounding variables, whose relative contribution to the observed familial trait may permit a better resolution of the immunological and genetic processes at play in Crohn's disease.

This study was supported by NIH grants DK46763, CA12800, DK43026, and AI07126, the Crohn's and Colitis Foundation of America, the Johnson Comprehensive Cancer Center, the Cedars-Sinai Board of Governor's Chair in Medical Genetics, and the Feintech Family Chair of Inflammatory Bowel Disease. Some of the results were obtained by using the program package SAGE, which is supported by a US Public Health Service Resource Grant (1P41RR03655) from the National Center for Research Resources. We acknowledge Loren C Karp for critical review of the manuscript, and Karin Reimann for laboratory experimentation.

Drs Braun and Targan are members of the Board of Directors of Prometheus Corporation, San Diego, California.

1 D'Haens GR, Geboes K, Peeters M, et al. Early lesions of recurrent Crohn's disease caused by infusion of intestinal contents in excluded ileum. Gastroenterology 1998;114:2627.

2 Prantera C, Zannoni F, Scribano ML, et al. An antibiotic regimen for the treatment of active Crohn's disease: a randomized, controlled clinical trial of metronidazole plus ciprofloxacin. Am $\mathcal{F}$ Gastroenterol 1996;91:328-32.

3 Rutgeerts P, Hiele M, Geboes K, et al. Controlled trial of metronidazole treatment for prevention of Crohn's recurrence after ileal resection. Gastroenterology 1995;108:161721 .

4 Janowitz HD, Croen EC, Sachar DB. The role of the fecal stream in Crohn's disease: an historical and analytic review.
Inflammatory Bowel Disease 1998;4:29-39. 
5 Gui GPH, Thomas PRS, Tizard MLV, et al. Two-yearoutcomes analysis of Crohn's disease treated with rifabutin and macro

6 Wayne LG, Hollander D, Anderson B, et al. Immunoglobulin A (IgA) and IgG serum antibodies to mycobacterial antigens in patients with Crohn's disease and their relatives. f Clin Microbiol 1992;30:2013-18.

7 Blaser MJ, Miller RA, Lacher J, et al. Patients with active Crohn's disease have elevated serum antibodies to antigen of seven enteric bacterial pathogens. Gastroenterology 1984 87:888-94.

8 Vannuffel P, Dieterich C, Naerhuyzen B, et al. Occurrence, in Crohn's disease, of antibodies directed against a speciesspecific recombinant polypeptide of Mycobacterium paratuberculosis. Clin Diag Lab Immunol 1994;1:241-3.

9 Liu Y, Van Kruiningen HJ, West AB, et al. Immunocytochemical evidence of Listeria, Escherichia coli, and Strep-
tococcus antigens in Crohn's disease. Gastroenterology tococcus antigens in

10 Elsaghier A, Prantera C, Moreno C, et al. Antibodies to Mycobacterium paratuberculosis-specific protein antigens

11 Pirzer U, Schonhaar A, Fleischer B, et al. Reactivity of infiltrating T lymphocytes with microbial antigens in Crohn's disease. Lancet 1991;338:1238-9.

12 Young CA, Sonnenberg A, Burns EA. Lymphocyte proliferation response to Baker's yeast in Crohn's disease. Digestion 1994;55:40-3.

13 Brandwein SL, McCabe RP, Cong Y, et al. Spontaneously colitic C $3 \mathrm{H} / \mathrm{HeJBir}$ mice demonstrate selective antibody reactivity to antigens of the enteric bacterial flora. $\mathcal{F}$ Immunol 1997;159:44-52.

14 Rath HC, Herfarth HH, Ikeda JS, et al. Normal luminal bacteria, especially bacteroides species, mediate chronic colitis, gastritis, and arthritis in HLA-B27/human beta $2 \mathrm{mi}-$ croglobulin transgenic rats. F Clin Invest 1996;98:945-53.

15 Herfarth HH, Mohanty SP, Rath HC, et al. Interleukin 10 suppresses experimental chronic, granulomatous inflammation induced by bacterial cell wall polymers. Gut 1996; 39:836-45.

16 Dianda L, Hanby AM, Wright NA, et al. T cell receptor-alpha,beta-deficient mice fail to develop colitis in the absence of a microbial environment. Am F Pathol 1997; 150:91-7.

17 Davidson IW, Lloyd RS, Whorwell PJ, et al. Antibodies to maize in patients with Crohn's disease, ulcerative colitis, and coeliac disease. Clin Exp Immunol 1979;35:147-8.

18 Knoflach P, Park BH, Cunningham R, et al. Serum antibodies to cow's milk proteins in ulcerative colitis and Crohn's disease. Gastroenterology 1987;92:479-85.

19 Falchuk KR, Isselbacher KJ. Circulating antibodies to bovine serum albumin in ulcerative colitis and Crohn's disease. Gastroenterology 1976;70:5-8.

20 Sonnenberg A. Occupational distribution of inflammatory bowel disease among German employees. Gut 1990;31: 1037-40.

21 Van Kruiningen HJ, Colombel JF, Cartun RW, et al. An in-depth study of Crohn's disease in two French families. in-depth study of Crohn's disease
Gastroenterology 1993;104:351-60.

22 Tysk C, Riedesel H, Lindgerg E, et al. Colonic glycoproteins in monozygotic twins with inflammatory bowel disease. Gastroenterology 1991;100:419-23.

23 Roth M-P, Petersen GM, McElree C, et al. Geographic origins of Jewish patients with inflammatory bowel disease. Gastroenterology 1989;97:900-4.

24 Yang H-Y, McElree C, Shanahan F, et al. Familial empiric risks for inflammatory bowel disease. Differences between Jews and non-Jews. Gut 1993;34:517-22.

25 Peeters M, Geypens B, Claus D, et al. Clustering of increased small intestinal permeability in families with Crohn's disease. Gastroenterology 1997;113:802-7.

26 Akolkar PN, Gulwani-Akolkar B, Heresbach D, et al. Differences in risk of Crohn's disease in offspring of mothers and fathers with inflammatory bowel disease. Am 7 Gastroenterol 1997;92:2241-4.

27 Toyoda H, Wang S-J, Yang H-Y, et al. Distinct associations of HLA class II genes with inflammatory bowel disease. of HLA class II genes with inflamterology 1993;104:741-8.

28 Yang H-Y, Vora KA, Targan SR, et al. Intercellular adhesion molecule 1 gene association with immunologic subsets of inflammatory bowel disease. Gastroenterology 1995;109: $440-6$
29 Plevy SE, Targan SR, Yang H-Y, et al. Tumor necrosis factor microsatellite define a Crohn's disease-associated haplotype on chromosome 6. Gastroenterology 1996;110:1053-

30 Bouma G, Poen AC, Garcia-Gonzalez MA, et al. HLADRB $1{ }^{\star} 03$, but not the TNFA -308 promoter gene polymorphism, confers protection against fistulising Crohn's disease. Immunogenetics 1998;47:451-5.

31 Cariappa A, Sands B, Forcione D, et al. Analysis of MHC class II DP, DQ and DR alleles in Crohn's disease. Gut 1998;43:210-15.

32 Roussomoustakaki M, Satsangi J, Welsh K, et al. Genetic markers may predict disease behavior in patients with ulcerative colitis. Gastroenterology 1997;112:1845-53.

33 Hugot J-P, Laurent-Puig P, Gower-Rousseau C, Groupe d'Etude Therapeutique des Affections Inflammatoires Digestives, et al. Mapping of a susceptibility locus for Crohn's disease on chromosome 16. Nature 1996;379:821-3.

34 Ohmen JD, Yang H-Y, Yamamoto KK, et al. Susceptibility locus for inflammatory bowel disease on chromosome 16 has a role in Crohn's disease, but not in ulcerative colitis. Hum Mol Genet 1996;5:1679-83.

35 Satsangi J, Parkes M, Louis E, et al. Two stage genome-wide search in inflammatory bowel disease provides evidence for susceptibility loci on chromosomes 3, 7 and 12. Nat Genet 1996;14:199-202.

36 Duerr RH, Barmada MM, Zhang L, et al. Linkage and association between inflammatory bowel disease and a locus association between inflammatory bowel disease and a locu
on chromosome 12. Am f Hum Genet 1998;63:95-100.

37 Duerr RH, Targan SR, Landers CJ, et al. Anti-neutrophil cytoplasmic antibodies in ulcerative colitis. Comparison with other colitides/diarrheal illnesses. Gastroenterology 1991;100:1590-6.

38 Yang H-Y, Rotter JI, Toyoda H, et al. Ulcerative colitis: a genetically heterogeneous disorder defined by genetic
(HLA class II) and subclinical (antineutrophil cytoplasmic antibodies) markers. F Clin Invest 1993;92:1080-4.

39 Shanahan F, Duerr RH, Rotter JI, et al. Neutrophil autoantibodies in ulcerative colitis: familial aggregation and genetic heterogeneity. Gastroenterology 1992;103:456-61.

40 Satsangi J, Landers CJ, Welsh KI, et al. The presence of anti-neutrophil antibodies reflects clinical and genetic heterogeneity within inflammatory bowel disease. Inflammatory Bowel Disease 1998;4:18-26.

41 Lindberg E, Magnusson KE, Tysk C, et al. Antibody (IgG, IgA, and IgM) to baker's yeast (Saccharomyces cerevisiae), yeast mannan, gliadin, ovalbumin, and betalactoglobulin in yeast mannan, gliadin, ovalbumin, and betalactoglobulin in monozygotic twin

42 Sendid B, Colombel JF, Jacquinot PM, et al. Specific antibody response to oligomannosidic epitopes in Crohn's disease. Clin Diag Lab Immunol 1996;3:219-26.

43 McKenzie H, Main J, Pennington CR, et al. Antibody to selected strains of Saccharomyces cerevisiae (baker's and brewer's yeast) and Candida albicans in Crohn's disease. Gut 1990;31:536-8

44 Quinton JF, Sendid B, Reumaux D, et al. AntiSaccharomyces cerevisiae mannan antibodies combined with antineutrophil cytoplasmic autoantibodies in inflammatory bowel disease: prevalence and diagnostic role. Gut matory bowel dis

45 Sendid B, Quinton JF, Charrier G, et al. AntiSaccharomyces cerevisiae mannan antibodies in familial Crohn's disease. Am f Gastroenterol 1998;93:1306-10.

46 Falconer DS. Introduction to quantitative genetics. 3rd ed. Essex: Longman Scientific and Technical Company, 1981

47 Sokal RR, Rohlf FJ. Biometry: the principles and practice of statistics in biological research. 3rd ed. New York: WH Freeman and Company, 1995.

48 Karlin S, Cameron EC, Williams PT. Sibling and parentoffspring correlation estimation with variable family size. Proc Natl Acad Sci USA 1981;78:2664-8.

49 Lillioja S, Mott DM, Zawadzki JK, et al. In vivo insulin action is familial characteristic in nondiabetic Pima Indians. Diabetes 1987;36:1329-35.

50 Hollander D, Vadheim CM, Brettholz E, et al. Increased intestinal permeability in Crohn's patients and their relatives: an etiologic factor? Ann Intern Med 1986;105: 883-5.

51 Ruemmele FM, Targan SR, Levy G, et al. Diagnostic accuracy of serological assays in pediatric inflammatory bowel disease. Gastroenterology 1998;115:822-9. 